\title{
Etnoconhecimento de plantas de uso medicinal por benzedeiras/benzedores e rezadeiras/rezadores de Anhembi e Mogi das Cruzes - SP
}

\author{
Sergio Zanata Carvalho ${ }^{1}$ \\ Luci Mendes de Melo Bonini ${ }^{2}$ \\ Renata Jimenez de Almeida-Scabbia ${ }^{3}$
}

\begin{abstract}
RESUMO
Estuda-se o uso de plantas medicinais por benzedeiras/ores e rezadeiras/ ores de dois municípios do estado de São Paulo, bem como se realiza uma reflexão sobre a perseguição que eles/elas sofreram no passado e, no presente, seu papel como agente de saúde. Trata-se de pesquisa exploratório-descritiva de abordagem qualitativa de corte transversal. Sete participantes responderam a uma entrevista semiestruturada. Os resultados mostram que ainda persiste o uso de plantas e que esse conhecimento foi passado de geração em geração. As plantas utilizadas são comuns em seus quintais, ou de amigos, até mesmo na feira, e as indicações terapêuticas são várias em forma de chás ou até mesmo ramos verdes utilizados em benzeções.
\end{abstract}

Palavras-chave: etnobotânica, religião, política pública.

Estudante do Curso de Ciências Biológicas na Universidade de Mogi das Cruzes, UMC. Dra. em Comunicação e Semiótica pela Pontifícia Universidade Católica de São Paulo, PUC-SP, docente no Programa de Mestrado em Políticas Públicas da Universidade de Mogi das Cruzes e docente colaboradora no Mestrado em Habitação: Tecnologia e Planejamento do Instituto de Pesquisas Tecnológicas de São Paulo, IPT- SP-USP.

3 Agrônoma pela Universidade Federal de Lavras, Mestre e Doutora em Biologia Vegetal pela Universidade Estadual Paulista Júlio de Mesquita Filho, UNESP, docente do Programa de Mestrado em Políticas Públicas da Universidade de Mogi das Cruzes, UMC. 


\title{
ETNO-KNOWLEDGE" OF PLANTS OF MEDICINAL USE BY PRAYERS AND MOURNERS FROM ANHEMBI AND MOGI DAS CRUZES-SP, BRAZIL
}

\begin{abstract}
This paper studied the use of medicinal plants by mourners and prayers in two municipalities in the State of São Paulo, as well as held a reflection on the persecution they suffered in the past and they/, in this, your role as a health agent. This is exploratory research-descriptive qualitative approach of cross section. Seven participants responded to a semi-structured interview. The results show that still persists using plants and that this knowledge was passed from generation to generation. The plants used are common in their yards, or friends, even at the fair, and the therapeutic indications are based on teas or even green branches used in prayer.
\end{abstract} Keyword: Ethnobotany, Mourners, Prayers.

\section{Introdução}

Benzedeiras e benzedores, rezadeiras e rezadores são pessoas devotadas e religiosas, geralmente católicas, porém não necessariamente frequentadora de igrejas. Essas pessoas, normalmente, possuem o domínio de rezas e ervas, fazendo chás, cataplasmas e massagens. O fenômeno da benzeção e da reza é uma manifestação de uma religiosidade popular que traz a cura ou o alívio para os problemas que afligem a população que acredita nessa prática. (AZEVEDO, 2015).

As mulheres, embora tenham sofrido inúmeros tipos de perseguição, têm sido curadoras, médicas, abortistas, anatomistas, enfermeiras, farmacêuticas e agricultoras de ervas há séculos em todo o ocidente, principalmente para aqueles onde qualquer forma de cura oficial jamais chega. (EHRENREICH \& ENGLISH, 1973).

Este trabalho tem como objetivos: levantar informações sobre o uso de plantas por benzedeiras e rezadeiras, assim como conhecer as plantas utilizadas pelas benzedeiras e rezadeiras do Divino, no município de Mogi das Cruzes e de Anhembi - estado de São Paulo e com isso resgatar informações sobre a utilização e o manejo das plantas. Assim, neste sentido, aproveita-se para 
fazer uma breve revisão histórica de como essas práticas podem ter surgido e como foram combatidas dentro da organização da Igreja Católica.

Este estudo se justifica na medida em que essa prática persiste há séculos dentro do processo da religiosidade popular brasileira e, por isso, deve ser estudada sempre que possível, a fim de se atualizar o conhecimento que se tem do uso de rezas, cantos e plantas que se mantém na tradição oral.

Entende-se que há uma grande contribuição para os estudos da religião a partir dos resultados aqui obtidos, uma vez que as plantas vêm acompanhando as rezadeiras e benzedeiras desde as atividades mais remotas nas tribos e porque, no cenário brasileiro atual, existe um movimento em direção ao reconhecimento das benzedeiras e rezadeiras como profissionais de Saúde desde 2009. (DUCATI e DIONÍSIO, 2012).

Com base na revisão de literatura de viés histórico e antropológico e de pesquisa de campo com sete participantes, os resultados mostraram que rezadeiras, rezadores, benzedeiras e benzedores utilizam-se de conhecimentos transmitidos de forma oral e o poder das plantas, normalmente surge aliado ao poder da palavra, rezas de vertente católica. Alguns escolhem plantas específicas, outros escolhem o que cultivam em seu próprio quintal.

\section{Rezadeiras e rezadores, benzedeiras e benzedores: origens históricas e práticas}

Há séculos as mulheres têm se mostrado profissionais da medicina utilizando-se de diferentes tipos de cuidados: na alimentação, na higiene, na cura de doenças e na saúde espiritual dos que estão à sua volta. A maternidade sempre despertou o cuidado e a dependência humana com a mãe e notadamente a mais longa entre os mamíferos, o que pode ter criado laços familiares mais profundos, tendo esses se estendido para a comunidade no entorno, fazendo assim emergir as benzedeiras, rezadeiras, conselheiras. (MACIEL \& GUARIM NETO, 2006). 
Nas comunidades distantes onde sequer chegavam padres para realizar o batismo, as pessoas viviam à sua própria sorte e, claro, sempre surgiram pessoas benevolentes que se dispuseram a ajudar, pois estão muito próximas à comunidade e portanto capazes de compreendem melhor os seus problemas.

A separação dessas mulheres do ato de cura deu-se lentamente. Minkowski (1992) afirma que a secularização dos hospitais foi comum no século $\mathrm{XV}$, pois conventos e mosteiros começaram a servir como hospitais, o que coloca em cena os homens como detentores do poder de cura. Essas clínicas ofereciam serviços de saúde para a comunidade da vizinhança, restando à mulher apenas o cuidado com a família. Assim, na medida em que os homens passaram a dominar o campo da saúde - o que resultou no nascimento das ciências médicas, as mulheres ficaram apenas com as funções menores nesta área. (EHRENREICH \& ENGLISH, 1973).

Com os homens no cenário das ciências da saúde e da Educação Médica, atividades lucrativas para a academia e para o reino, teve início a caça às bruxas que varreu a Europa a partir do final do século XV, data essa que leva em consideração o ano de 1484 em que foi publicado o livro Malleus Maleficarum, iniciativa financiada pela Igreja e pelo Estado. (VILLAS, 2015; CÂMARA et al., 2016).

No Brasil, o surgimento dos benzedores ou benzedeiras no Brasil pode ter ocorrido da junção de cultura ocidental, na figura do colonizador e dos índios e negros com seus diferentes conhecimentos de rituais e plantas medicinais. (AZEVEDO, 2017). Foi a partir do século XVII, no Brasil, que se identificou o uso de recursos vegetais manipulados por benzedores, parteiras, raizeiros gerando uma fonte rica de pesquisa para os estudos etnobotânicos. Os benzedores fazem a utilização das plantas tanto para cura quanto para proteção, atuando como intermediários entre o ser humano e o sagrado, conservando o ritual de preces, cruzes e fórmulas. (MACIEL \& GUARIM-NETO, 2006).

$\mathrm{Na}$ esteira da criminalização das práticas medicinais por pessoas não habilitadas, o Brasil República, já entre o final do século XIX e início do XX, apontou como delituosas as práticas 
da medicina sem a devida habilitação, ou seja, o Estado controlava diferentes práticas de cura que emergiram da diversidade cultural e claro, da biodiversidade da flora brasileira. O Código Penal de 1890 inscreveu e penalizou em seus artigos $156^{4}$ e $158^{5}$, o exercício irregular da medicina e a prescrição de remédios preparados a partir de quaisquer substâncias, e o artigo $157^{6}$, que proibia a prática do espiritismo, que segundo descrito, usava a magia. (GOMES, 2013).

Nas décadas de 50 até 70 ocorria o combate contra as práticas ilícitas, que possuíam como foco principal, curandeiros e outros praticantes da medicina popular. Após 1970 ervateiros, benzedeiros e outros praticantes, passaram a ter um papel secundário na sociedade, deixando de ser o alvo principal da justiça. Benzedeiros, raizeiros e outros curandeiros continuaram a existir, mas não representavam mais riscos ao Estado ou médicos diplomados. (CARVALHO, 2005).

4 Art. 156 - Exercer a medicina em qualquer de seus ramos, a arte dentária ou a farmácia; praticar a homeopatia, a dosimetria, o hipnotismo ou magnetismo animal, sem estar habilitado segundo as leis e regulamentos. Penas - de prisão celular por um a seis meses, e multa de $100 \$ 000$ a 500\$000. Parágrafo único: Pelos abusos cometidos no exercício ilegal da medicina em geral, os seus atores sofrerão, além das penas estabelecidas, as que forem impostas aos crimes que derem casos.

5 Art. 158 -Ministrar ou simplesmente prescrever, como meio curativo, para uso interno ou externo, e sob qualquer forma preparada, substância de qualquer dos reinos da natureza, fazendo ou exercendo assim, o ofício do denominado curandeirismo. Penas - de prisão celular por um a seis meses, e multa de $100 \$ 000$ a $500 \$ 000$.

Parágrafo único: Se do emprego de qualquer substância resultar a pessoa privação ou alteração, temporária ou permanente, de suas faculdades psíquicas ou funções fisiológicas, deformidades, ou inabilitação do exercício de órgão ou aparelho orgânico, ou, em suma, alguma enfermidade: Penas - de prisão celular por um a seis anos, e multa de $200 \$ 00$ a $500 \$ 000$.

Se resultar morte: Pena - de prisão celular por seis a vinte e quatro anos.

6 Art. 157 - Praticar o espiritismo, a magia e seus sortilégios, usar de talismãs e cartomancias, para despertar sentimentos de ódio ou amor, inculcar cura de moléstias curáveis ou incuráveis, enfim, para fascinar e subjugar a credulidade pública: Penas - de prisão celular de um a seis meses, e multa de $100 \$ 000$ a 500\$000.

Parágrafo 1a Se, por influência, ou por consequência de qualquer destes meios, resultar ao paciente privação ou alteração, temporária ou permanente, das faculdades psíquicas. Penas - de prisão celular por um ano a seis anos, e multa de $200 \$ 000$ a 500\$000. Parágrafo 2o Em igual pena, e mais na privação de exercício da profissão por tempo igual ao da condenação, incorrerá o médico que diretamente praticar qualquer dos atos acima referidos, ou assumir a responsabilidades deles. (...) 
Foram muitas décadas até a chegada do século XXI e o reconhecimento do papel das benzedeiras no Brasil, já se vê atualmente algumas cidades brasileiras - nos estados do Paraná e do Ceará - reconhecerem as benzedeiras como profissionais da saúde. (GREENME, 2017). Equipes da Saúde da Família reconhecem que a benzeção faz parte da diversidade cultural do povo brasileiro que ainda tem a sua volta uma variada biodiversidade de flora. (ASSUNÇÃO \& RODRIGUES, 2017)

Ehrenreich e English (1973) lembram apropriadamente, que muitos remédios testados por essas mulheres foram perdidos, no entanto outros há, cujos usos na farmacologia atual são efetivos, entre os quais encontram-se os digestivos, como a camomila, os anti-inflamatórios e os analgésicos, dos quais a Beladona é um exemplo.

Emplastos, chás com diferentes materiais e plantas exigem que elas os tenha ao seu alcance, por isso muitas acabam tendo nos seus quintais uma gama variada de plantas que elas mesmas cultivam por estarem consagradas há muito pela sabedoria popular como plantas de cura. (ARAÚJO \& AGUIAR, 2014).

\section{A Etnobotânica}

O uso medicinal das plantas é comum em todo o Brasil (GUARIM NETO 1996; DI STASI \& HIRUMA-LIMA, 2002; GUARIM NETO \& MORAIS, 2003; PASA et al., 2005; FRANÇA et al, 2008; LORENZI \& MATOS, 2008; ALMEIDA et al., 2009; OLIVEIRA et al., 2010; CUNHA \& BORTOLOTTO, 2011; COSTA \& MARINHO, 2016; BRITO et al., 2017) e atualmente vem crescendo o interesse em integrá-lo ao uso na medicina oficial. (VEIGA JUNIOR, 2008; BRUNING et al., 2012; FONTENELE et al., 2013; VARELA \& AZEVEDO, 2014; MATTOS et al., 2016). Muitos motivos levam as pessoas a utilizarem plantas com fins terapêuticos, seja de ordem médica, social, cultural, econômica ou, ainda, filosófica. (MING, 2003),

Segundo Brandon et al. (2005) o Brasil é detentor de elevada biodiversidade distribuída por vários biomas e ecossistemas. Então 
no decorrer dos anos diversas plantas medicinais foram relatadas para cura e proteção, sempre aumentando o valor e a história da etnobotânica (SILVA, et al., 2015).

Segundo Beck e Ortiz (1997) a etnobotânica compreende o estudo das sociedades humanas, passadas e presentes, e suas interações ecológicas, genéticas, evolutivas, simbólicas e culturais com as plantas. $\mathrm{O}$ estudo da etnobotânica busca não só abranger o registro do uso dos recursos vegetais presentes em determinada área, mas as formas de manejo como são empregadas por comunidades tradicionais. O conhecimento repassado de geração a geração nas comunidades tradicionais, sobre os recursos terapêuticos das plantas encontradas em seu ambiente natural pode ser um instrumento importante, como por exemplo, para indústria farmacêutica na elaboração de novos medicamentos. (ARGENTA et al., 2011).

A etnobotânica é citada na literatura como sendo um dos caminhos alternativos que mais evoluiu nos últimos anos para a descoberta de produtos naturais bioativos (MACIEL,2002). Além de tudo isso, a preservação dos conhecimentos, ou seja o patrimônio cultural, também é muito importante, como afirma Santos (2009).

A medicina popular pode ser considerada como uma medicina sacralizada, pois envolve sistemas diferentes de crenças e portanto as plantas tornam-se entes sagrados, mágicos, com poderes curativos. A elas são atribuídas propriedades que vão além das classificações taxonômicas, fórmulas químicas e análises farmacológicas. Nesse contexto entram os curadores representados, por exemplo, por rezadeiras e rezadores, benzedeiras e benzedores, como instrumentos na utilização dessas plantas nos rituais de cura. (CAMARGO, 2014).

\section{Método}

A pesquisa foi de natureza exploratório-descritiva, de abordagem qualitativa de corte transversal. Participaram da pesquisa sete sujeitos, seis mulheres e um homem, maiores de 18 anos, que responderam a uma entrevista semiestruturada, desenvolvida 
especificamente para a pesquisa. Os participantes foram selecionados por meio de uma amostragem intencional que segundo Tongco (2007) é um método não probabilístico de escolha de informantes, de acordo com as qualidades que possuem e que sejam fundamentais para responder questões específicas da pesquisa. Essas questões foram bastante discutidas de modo que a amostra fosse eficiente (idem, ibidem) para o propósito da etnobotânica.

Foi utilizado um Termo de Consentimento Livre e Esclarecido assinado pelos sujeitos participantes e o projeto foi aprovado pelo Comitê de Ética em Pesquisa com seres humanos sob o $\mathrm{n}^{\circ}$ 1.602.959. Para as respostas abertas, a abordagem foi qualitativa e resultou numa tabela em que se caracterizou as plantas utilizadas em cada ritual, e descreveu-se o ritual, utilizando as palavras de cada participante.

\subsection{Locais de Coleta de Dados}

Para a pesquisa foram escolhidos dois município: Mogi das Cruzes, na região leste metropolitana de São Paulo e Anhembi, na região do médio Tietê no estado de São Paulo. Os municípios foram escolhidos em virtude de apresentarem uma semelhança com relação à devoção do Divino Espírito Santo e a dimensão dada a esta devoção nas festas que acontecem entre os meses de maio e junho, por ocasião da celebração de Pentecostes pela Igreja Católica. Uma hipótese que norteia este trabalho é a de que a proximidade com as celebrações ao Divino Espírito Santo pode ser um elemento detonador das práticas de cura utilizando-se a natureza.

i) Mogi das Cruzes é um município situado na região leste da Grande São Paulo, possui clima sub tropical, com população estimada de 424.633 habitantes, com um Índice de Desenvolvimento Humano Municipal (IDHM) de 0,783 e com área territorial de $712,541 \mathrm{~km}^{2}$ (IBGE, 2015), distante $63 \mathrm{Km}$ da capital e cortada pelo Rio Tietê. A denominação Mogi vem da língua indígena das tribos locais e significa rio das cobras (mboygi). 
Localizada entre as serras do Mar e do Itapeti, com a maior área verde da região leste da Grande São Paulo, Mogi das Cruzes, uma das primeiras cidades do país, tem sua história permeada por acontecimentos socioeconômicos que acompanharam os processos produtivos e econômicos mais significativos do país. (GUIMARÃES et al.,2006).

Formou-se em torno de um aldeamento indígena durante o período colonial em meados de 1560 . Os livros de história da cidade relatam que o povoado começou a crescer em 1601 com a chegada do colonizador Gaspar Vaz, que abriu os primeiros caminhos de acesso a São Paulo. Em 1611 o aldeamento tornou-se vila. E no ano de 1633, foi construída a igreja da ordem primeira do Carmo. Onde deu início aos costumes cristãos. (RODRIGUES, 2006).

Em Mogi das Cruzes além das benzedeiras, as rezadeiras da festa do Divino, também contribuem para esse conhecimento, uma vez que segundo Mariano (2009) a festividade, apesar de subordinada à religião católica, mantém o caráter de culto aos vegetais e à natureza. De acordo com Bonini e Prieto (2016) o ofício de ser benzedeira ou rezadeira não tem origem apenas na Igreja Católica, mas em várias vertentes religiosas do mundo.

ii) Anhembi é um município localizado no centro do Estado de São Paulo, possui clima tropical, com população estimada de 6.397 habitantes, com um IDHM de 0,721 e uma área territorial de $736.557 \mathrm{Km}^{2}$. (IBGE, 2015).

Localizada entre Botucatu e Piracicaba, a cidade é banhada pelos rios Tietê, Alambari e do Peixe e tem como base econômica a criação de gado de corte e de leite, produção de cana de açúcar e laranja. O município faz parte da Hidrovia Tietê Paraná e dista 238 quilômetros da capital.

Fundada por bandeirantes às margens do Rio Tietê, teve como denominação inicial Capela Nossa Senhora Padroeira do Arraial Senhora dos Remédios da Ponte do Tietê. A denominação Anhembi tem origem indígena e significa Rio dos Inhambus. (IBGE, 2013). 
No município de Anhembi, em virtude de a devoção ao Espírito Santo ser uma prática social, explicita Almeida (2008) que a população católica em sua grande maioria, formula sua própria experiência social em torno da Irmandade do Divino - homens que, ao longo de mais de cem anos rezam pela cura de doenças e para o alcance de muitas graças.

\section{Resultados e discussões}

Foram entrevistadas três rezadeiras e uma benzedeira em Mogi das Cruzes e duas benzedeiras e um benzedor em Anhembi, totalizando sete participantes com apenas uma com idade menor que sessenta anos. Tal resultado concorda com Almeida et al. (2009) afirmando que mulheres são as principais detentoras do conhecimento sobre as plantas medicinais.

Após coletados os dados, os mesmos foram analisados e transformados em tabelas e gráficos para uma melhor visualização. O tempo de ofício de cada participante variou e foi dividido de um a nove anos, com quatro participantes, de 10 a 20 anos com dois participantes e com mais de 20 anos de prática, apenas um participante.

Questionados com quem aprenderam a técnica, assim surgiram as respostas: um afirma que aprendeu com Deus, uma outra, com membros da própria família, uma outra, com outras rezadeiras e quatro afirmam ter aprendido com outras pessoas. Tais relacionamentos sociais permitem o enriquecimento do conhecimento pessoal a respeito dos usos e aplicações dos recursos naturais. (CUNHA \& BORTOLOTTO, 2011). A tradição oral é sempre apontada como forma de transmissão dos conhecimentos (CÂMARA et al., 2016) frequentemente quanto se trata de usos e funções das plantas medicinais (BRITO et al., 2017; MARIN \& SCORSOLINI-COMIN, 2017), mas há outro caso em que uma das benzedeiras afirma que seu conhecimento vem de Deus, assim como achados em Gomes et al (2017) uma participante afirmou também que seu conhecimento vinha de Deus e dos sonhos. 
O material para o ritual dos benzimentos e das rezas são encontrados em diferentes lugares: quatro participantes afirmaram que colhem direto do próprio quintal, uma afirma que compra na feira, outra busca com amigos e um deles afirmou que qualquer lugar onde se encontrar uma folha verde. Os rituais são compostos de ramos verdes, orações e falas rimadas ou não. (MACIEL \& GUARIM NETO, 2006)

Muitos afirmaram utilizar rezas advindas da religião católica como o Credo, o Pai Nosso e a Ave Maria, sempre acompanhados da persignação, assim também afirmam Câmara et al. (2016). Alia-se, desta forma, o poder de cura da planta e da palavra.

Sousa (2014) afirma que é mais comum entre os homens benzer animais, no caso deste estudo também, o benzedor afirmou que só benze animais, geralmente gado, mas outras espécies também surgem para suas rezas, o animal não precisa estar presente, apenas suas características físicas e o lugar onde se encontra. Geralmente, quem procura os benzimentos e rezas são pessoas necessitadas de curas, como encontrado também por Maciel \& Guarim Neto (2006). Vizinhança, donos de gado e pessoas que muitas vezes acabam sabendo por meio de outros que receberam alguma graça ou alguma cura.

Câmara et al (2016) citam que a procura por essas pessoas se dá, não só porque as regiões são mais pobres - o que pode não estar de acordo com os achados desta pesquisa, já que as cidades aqui apresentadas apresentam um bom IDHM - mas também porque são pessoas que vivem mais próximas dos seus consulentes, ou porque algumas doenças, como o mau-olhado, por exemplo, médicos não curam.

Quanto as características botânicas, as famílias mais citadas foram Asteraceae (Mikania sp - guaco e Vernonia sp - assa-peixe), Lamiaceae (Mentha spp - hortelã e poejo) e Moraceae (Ficus sp - figueira e Morus nigra L. - amoreira).

Chama a atenção a utilização de espécies exóticas como a Mentha spp e Morus nigra, diante de toda a diversidade nativa existente. De acordo com Medeiros et al. (2017), isso pode ocorrer para preencher lacunas deixadas pelas plantas nativas, para 
diversificar o repertório de plantas, ou pela vantagem competitiva em relação às nativas. Entretanto não se pode esquecer que uma vez que as informações são orais, existe uma contribuição dos processos migratórios que trazem consigo plantas e informações sobre as mesmas.

A parte mais utilizadas foram as folhas, o que também foi constatado por Costa \& Marinho (2016) em seu trabalho na Paraíba.

Para finalizar, fez-se um quadro (Quadro 1) mostrando a família da planta ou plantas utilizadas seu gênero e nome popular das plantas utilizadas, além de sua função e seu preparo. Não foi possível a identificação das espécies devido ao fato de não ter ocorrido coleta do material, pois as entrevistas não ocorreram nas residências e sim em reuniões e por e-mails, por preferência dos entrevistados.

\section{Quadro 1. Plantas: indicações terapêuticas, família botâ- nica, nome científico, popular e modo de preparo es de cura.}

\begin{tabular}{|l|l|l|l|l|}
\hline $\begin{array}{l}\text { Indicações } \\
\text { Terapêuticas }\end{array}$ & Família & $\begin{array}{l}\text { Nome } \\
\text { Cientí- } \\
\text { fico }\end{array}$ & $\begin{array}{l}\text { Nome } \\
\text { Popular }\end{array}$ & Modo de Preparo \\
\hline $\begin{array}{l}\text { Anestesiar o } \\
\text { dente do bebê }\end{array}$ & $\begin{array}{l}\text { Lamia- } \\
\text { ceae }\end{array}$ & $\begin{array}{l}\text { Mentha } \\
s p\end{array}$ & hortelã & $\begin{array}{l}\text { Aquecer, colocar em um } \\
\text { paninho e passar na gen- } \\
\text { giva. }\end{array}$ \\
\hline Benzer erisipela & ---- & ---- & $\begin{array}{l}\text { qualquer } \\
\text { ramo } \\
\text { verde }\end{array}$ & $\begin{array}{l}\text { Colhe qualquer ramo verde } \\
\text { no quintal }\end{array}$ \\
\hline $\begin{array}{l}\text { Matar bicheira } \\
\text { do gado }\end{array}$ & ---- & ---- & $\begin{array}{l}\text { qualquer } \\
\text { folha } \\
\text { verde }\end{array}$ & $\begin{array}{l}\text { Três folhas uma de cada } \\
\text { vez falar: “Que essa bi- } \\
\text { cheira vá para frente que } \\
\text { nem essa folha vai.” e jo- } \\
\text { ga-se a folha para trás. }\end{array}$ \\
\hline $\begin{array}{l}\text { Secar as ver- } \\
\text { rugas }\end{array}$ & $\begin{array}{l}\text { Mora- } \\
\text { ceae }\end{array}$ & Ficus $s p$ & figueira & $\begin{array}{l}\text { Descascar o galho da fi- } \\
\text { gueira ainda verde, fazer } \\
\text { orações pensando na pessoa } \\
\text { e colocar para secar. Quan- } \\
\text { do o galho da figueira secar } \\
\text { a verruga cai. }\end{array}$ \\
\hline
\end{tabular}


e rezadeiras/rezadores de Anhembi e Mogi das Cruzes - SP

\begin{tabular}{|c|c|c|c|c|}
\hline $\begin{array}{l}\text { Indicações } \\
\text { Terapêuticas }\end{array}$ & Família & $\begin{array}{l}\text { Nome } \\
\text { Cientí- } \\
\text { fico }\end{array}$ & $\begin{array}{l}\text { Nome } \\
\text { Popular }\end{array}$ & Modo de Preparo \\
\hline \multirow{8}{*}{$\begin{array}{l}\text { Reorganizar } \\
\text { as funções dos } \\
\text { órgãos }\end{array}$} & $\begin{array}{l}\text { Astera- } \\
\text { ceae }\end{array}$ & $\begin{array}{l}\text { Verno- } \\
\text { nia sp }\end{array}$ & $\begin{array}{l}\text { assa-pei- } \\
\text { xe }\end{array}$ & \multirow{8}{*}{$\begin{array}{l}\text { Colher as folhas pela ma- } \\
\text { nhã ou após o por do sol. }\end{array}$} \\
\hline & $\begin{array}{l}\text { Equise- } \\
\text { taceae }\end{array}$ & $\begin{array}{l}\text { Equise- } \\
\text { tum sp }\end{array}$ & $\begin{array}{l}\text { cavali- } \\
\text { nha }\end{array}$ & \\
\hline & $\begin{array}{l}\text { Lamia- } \\
\text { ceae }\end{array}$ & $\begin{array}{l}\text { Mentha } \\
\text { sp }\end{array}$ & hortelã & \\
\hline & $\begin{array}{l}\text { Lamia- } \\
\text { ceae }\end{array}$ & $\begin{array}{l}\text { Mentha } \\
\text { sp }\end{array}$ & poejo & \\
\hline & $\begin{array}{l}\text { Mora- } \\
\text { ceae }\end{array}$ & $\begin{array}{l}\text { Morus } \\
\text { sp }\end{array}$ & $\begin{array}{l}\text { amora } \\
\text {-branca }\end{array}$ & \\
\hline & $\begin{array}{l}\text { Myrta- } \\
\text { ceae }\end{array}$ & $\begin{array}{l}\text { Psidium } \\
\text { guajava }\end{array}$ & goiaba & \\
\hline & Poaceae & $\begin{array}{l}\text { Sac- } \\
\text { charum } \\
\text { officina- } \\
\text { rum }\end{array}$ & $\begin{array}{l}\text { cana-de } \\
\text {-açúcar }\end{array}$ & \\
\hline & Rutaceae & $\begin{array}{l}\text { Ruta } \\
\text { graveo- } \\
\text { lens }\end{array}$ & arruda & \\
\hline Tosse & $\begin{array}{l}\text { Astera- } \\
\text { ceae }\end{array}$ & $\begin{array}{l}\text { Mikania } \\
\text { sp }\end{array}$ & guaco & Chá \\
\hline $\begin{array}{l}\text { Infecção de } \\
\text { garganta }\end{array}$ & $\begin{array}{l}\text { Mora- } \\
\text { ceae }\end{array}$ & $\begin{array}{l}\text { Morus } \\
\text { sp }\end{array}$ & $\begin{array}{l}\text { amora } \\
\text {-branca }\end{array}$ & Chá \\
\hline Dor de cabeça & $\begin{array}{l}\text { Costa- } \\
\text { ceae }\end{array}$ & $\begin{array}{l}\text { Costus } \\
\text { sp }\end{array}$ & $\begin{array}{l}\text { caninha- } \\
\text { do-brejo }\end{array}$ & Chá \\
\hline
\end{tabular}

Como apresentado por Lorenzi\& Matos (2008) a Organização Mundial da Saúde (OMS), recomenda aos órgãos responsáveis pela saúde pública de cada país que: a) procedam levantamentos regionais das plantas usadas na medicina popular tradicional e identifique-as botanicamente; b) estimulem e recomendem o uso daquelas que tiverem comprovadas sua eficiência e segurança terapêutica; c) desaconselhem o emprego das práticas da medicina popular consideradas inúteis ou prejudiciais; d) desenvolvam programas que permitam cultivar e utilizar as plantas selecionadas na forma de preparação dotadas de eficácia segurança e qualida- 
de: o que demonstra a utilidade da tabela com seu nome popular, família, gênero, função e preparo.

Oliveira et al. (2016) também encontrou entre as plantas mais utilizadas arruda e hortelã, além de cânfora, carqueja, malva e pata de vaca. Segundo Maciel \& Guarim Neto (2006) são o capim-guiné, alecrim, alfazema, alfavaca, comigo-ninguém-pode, espada-de-São-Jorge e folha-da-fortuna. Os mesmos autores também identificaram que além do chá, há benzimentos com banhos e xaropes.

Di Stasi \& Hiruma-Lima (2002) em pesquisa com comunidades no estado do Amazonas e de São Paulo obtiveram resultados que alinham os nomes populares, os dados botânicos relacionando-os à medicina tradicional encontrada nesta pesquisa. Lorenzi \& Matos (2008) também descrevem plantas medicinais brasileiras, nativas ou exóticas, cujos usos medicinais também coincidem com este trabalho, à exceção da cana de açúcar e da amora branca.

Vários autores mostraram a conexão das plantas medicinais com a religião, embora grande parte dos estudos relacionem plantas medicinais aos cultos afros.

\section{Considerações finais}

Este estudo mostrou a utilização de plantas para o uso medicinal por rezadeiras e benzedeiras por meio de seu conhecimento empírico, passado de geração a geração por familiares, amigos, vizinhos e outros conhecidos. Os rituais vão de uso das plantas como infusões, chá e outros preparos, podem ainda ser acrescidos de rezas, orações das religiões que os participantes praticam ou ainda gestos.

Rezadeiras e benzedeiras têm uma longa trajetória histórica de altos e baixos: iniciaram com o cuidado da família e da vizinhança, expandiram seus saberes e ensinamentos ao longo de séculos e tão logo a razão foi dando lugar ao cuidado elas estiveram fadadas à perseguição. As academias, cujo viés era eminentemente masculino, deram nascimento à educação médica - racional e 
técnica e, então, com apoio da Igreja e do Estado, acabaram por criminalizar as práticas e conhecimentos já estabelecidos por essas mulheres e homens. Muito desse conhecimento se perdeu, outros foram, aos poucos sendo resgatados e acabaram por fazer parte da farmacologia contemporânea.

Detectou-se que as plantas utilizadas pelos participantes desta pesquisa são relativamente comuns em seus quintais. Quando essas pessoas não têm essas plantas próximas elas plantam ou procuram com amigos e até mesmo na feira.

Como se viu, há indicações de que o uso das plantas, ou do conhecimento etnobotânico é incentivado pelos profissionais de saúde e com base em algumas informações colhidas muitos avanços científicos podem inovar no cenário do uso das plantas com finalidades medicinais.

As atividades das rezadeiras/rezadores e dos benzedores/benzedeiras pode variar, mas percebeu-se que mesmo em cidades com alto IDH-M, onde se pressupõe boa infraestrutura de saúde e educação e boa qualidade de vida ainda é possível encontrá-los/las.

O autor e as autoras agradecem a participação de todos os informantes desta pesquisa e à FAEP, Fundação de Amparo ao Ensino e à Pesquisa de Mogi das Cruzes, pela bolsa concedida.

\section{Referências}

ALMEIDA, L. N. Rio Tietê - Estrada líquida dos romeiros do Divino Espírito Santo. 2008. Dissertação (Mestrado em Ciências Sociais). PUC, São Paulo, 2008.

ALMEIDA, N. F. L.; SILVA, S. R. S.; SOUZA, J. M.; QUEIROZ, N. P. N.; MIRANDA, G. S.; OLIVEIRA, H. B. Levantamento etnobotânico de plantas medicinais na cidade de Viçosa, MG. Revista Brasileira de Farmácia, v.90, n.4, p.316-320, 2009.

ARAÚJO, J. S.; AGUIAR, R. S. As benzedeiras no assentamento Itamarati. In: Anais do ENEPEX, $8^{\circ}$ ENEPE UFGD e $5^{\circ}$ EPEX UEMS. 2014. Dourados, MS. 2014. Disponível em: http://eventos.ufgd.edu.br/enepex/anais/arquivos/296. pdf Acesso em: 12 jul. 2017. 
ARGENTA, S. C.; ARGENTA, L. C.; GIACOMÉLI, S. R; CEZAROTTO, V.C . Plantas Medicinais: Cultura Popular Versus Ciência. Vivências, v. 7, p. 51-60, 2011.

ASSUNÇÃO, L. M.; RODRIGUES, L. R. Benzedeiras e Equipe Saúde da Família: a complexidade do processo saúde-doença no SUS. In. Anais do $\mathbf{3}^{\circ}$. Fórum de Direitos Humanos e Saúde Mental. ABRASME. 28-30 jun/2017. Florianópolis, SC. 2017. Disponível em: http://www.direitoshumanos2017. abrasme.org.br/resources/anais/8/1491004445 ARQUIVO_ResumoExpandido-ABRASME.pdf. Acesso em: 12 dez. 2017.

AZEVEDO, G. X. Benzedeiras e a prática da benzeção no contexto das ciências das religiões. Protestantismo em Revista, v. 36. p. 108-117, 2015. Disponível em: http://www.periodicos.est.edu.br/index.php/nepp/article/view/2386/2324. Acesso em: 21 jul. 2017.

AZEVEDO, G. X. As benzedeiras na tecitura da cultura, religião e medicina popular. 2017. Tese (doutorado) PontifíciaUniversidade Católica de Goiás. Programa de Pós Graduação Stricto Sensu em Ciências da Religião. Gioânia. 2017.

BECK, H. T.; ORTIZ, A. 1997. Proyecto etnobotánico de La comunidad Awáen El Ecuador. Pp. 159-176. In: M. Rios \& H.B. Pedersen (eds.). Uso y Manejo de Recursos Vegetales. Memorias del II Simposio Ecuatoriano de Etnobotánica y Botánica Economica, Quito.

BONINI, L. M. M. O ofício de rezar em Mogi das Cruzes. In: BONINI, L. M. M. \& PIETRO, R. 2015. Rezadeiras e rezadores da Festa do Divino Espírito Santo em Mogi das Cruzes, SP: os saberes e fazeres como patrimônios. São Paulo: Editae. 2015. pp.27-33

BRANDON K.; FONSECA G. A. B; RYLANDS, A. B. S.; SILVA J. M. C. Conservação brasileira: desafios e oportunidades. Megadiversidade, v.1, p. 7-13, 2005.

BRASIL. Instituto Brasileiro de Geografia e Estatística. IBGE (cidades). Anhembi. Disponível em: https://cidades.ibge.gov.br/brasil/sp/anhembi/panorama. Acesso em: 12 dez. 2017.

BRASIL. Instituto Brasileiro de Geografia e Estatística. IBGE (cidades). Mogi das Cruzes. Disponível em: https://cidades.ibge.gov.br/brasil/sp/mogi-das-cruzes/panorama Acesso em: 12 dez. 2017.

BRITO, M. F. M.; MARÍN, E. A.; CRUZ, D. D. Plantas medicinais nos assentamentos rurais em uma área de proteção no litoral do nordeste brasileiro. Ambiente \& Sociedade, v. 20. n. 1, p. 83-104, 2017.

BRUNING, M. C. R.; MOSEGUI, G. B. G.; VIANNA, C. M. M. A utilização da fitoterapia e de plantas medicinais em unidades básicas de saúde nos mu- 
nicípios de Cascavel e Foz do Iguaçu - Paraná: a visão dos profissionais de saúde. Ciência \& Saúde Coletiva, v. 17, n. 10, p. 2675-2685, 2012.

CÂMARA, Y. R.; MINGO, C. S.; CÂMARA, Y. M. R. Das bruxas medievais às benzedeiras atuais: a oralidade como manutenção da memória na arte de curar - uma pesquisa exploratória. Boitatá - Revista do GT de Literatura Oral e Popular da ANPOLL, n. 22, p. 221-236, 2016

CAMARGO, M. T. L. A. As plantas medicinais e o sagrado - A Etnofarmacobotânica em uma revisão historiográfica da medicina popular no Brasil. $1^{\mathrm{a}}$. ed. São Paulo: Ícone Editora, 2014.

CARVALHO, A. C. D. Feiticeiros, burlões e mistificadores: criminalidade e mudança das práticas populares de saúde em São Paulo, 1950-1980. Editora UNESP, São Paulo, 2005.

COSTA, J.C.; MARINHO, M.G.V.. Etnobotânica de plantas medicinais em duas comunidades do município de Picuí, Paraíba, Brasil. Revista brasileira de plantas medicinais, v. 18, n. 1, p. 125-134, 2016. Disponível em http://www. scielo.br/scielo.php?script $=$ sci arttext\&pid $=$ S1516-05722016000100125\&lng=pt\&nrm=iso Acesso em: 02 jan. 2018.

CUNHA, Simone Alves da; BORTOLOTTO, Ieda Maria. Etnobotânica de Plantas Medicinais no Assentamento Monjolinho, município de Anastácio, Mato Grosso do Sul, Brasil. Acta Bot. Bras., Feira de Santana, v. 25, n. 3, p. 685-698, Sept. 2011 . Available from <http://www.scielo.br/scielo. php?script $=$ sci_arttext\&pid=S0102-33062011000300022\&lng=en\&nrm $=$ iso $>$. access on 03 Jan. 2018.

DI STASI, L. C.; HIRUMA-LIMA, C. A. Plantas medicinais na Amazônia e na Mata Atlântica. São Paulo: EdUNESP. 2002.

DUCATI, A. e DIONíSIO, B. Benzedeiras são consideradas profissionais de saúde no Paraná. Portal G1. 11.05.2012. Disponível em: http://g1.globo.com/ $\mathrm{pr} /$ parana/noticia/2012/05/benzedeiras-sao-consideradas-profissionais-da-saude-no-parana.html. Acessado em: 12.12.2017.

EHRENREICH, B.; ENGLISH, D. Witches, midwides, and nurses - a history of women healers. The Feminist Press. New York. NY.1973

FONTENELE, R. P; SOUSA, D. M. P.; CARVALHO, A. L. M.; OLIVEIRA, F.A. Fitoterapia na Atenção Básica: olhares dos gestores e profissionais da Estratégia Saúde da Família de Teresina (PI), Brasil. Ciência e Saúde Coletiva, v.18, n. 8, p. 2385-2394, 2013.

FRANÇA, I.; ALVES, J.; SANTOS, R.; SOUSA, V. Medicina popular: benefícios e malefícios das plantas medicinais. Revista Brasileira de Enfermagem, v. 61, n. 2, p. 201-208, 2008.

GOMES, A. O processo de secularização do Brasil no limiar da República e a criminalização do espiritismo. Sacrilegens, v. 10, n. 1, p.83-93, 2013. 
Disponível em: http://www.ufjf.br/sacrilegens/files/2014/01/10-1-7.pdf. Acesso em: 12 dez. 2017.

GOMES, T. B.; PORTUGAL, A. S.; PINTO, L. J. S. Plantas utilizadas por uma Benzedeira em Nova Friburgo, Rio de Janeiro, Brasil. Natureza online, v.15, n. 1, p. 019-027, 2017.

GREENME. Você sabia que as benzedeiras tem já seu ofício legalizado? Disponível em https://www.greenme.com.br/viver/saude-e-bem-estar/3331-voce-sabia-benzedeiras-oficio-legalizado. Acesso em: $12 \mathrm{dez} .2017$.

GUARIM NETO, G. Plantas medicinais do Estado do Mato Grosso. Brasília: ABEAS. 1996.

GUARIM NETO, G.; MORAIS, R. G. Recursos medicinais de espécies do cerrado de Mato Grosso: um estudo bibliográfico. Acta Botanica Brasilica, v. 17, n. 4, p. 561-584. 2003.

GUIMARÃES, E. O centro histórico de Mogi das Cruzes como instrumento de compreensão da história sócio cultural do município. In: Anais XVIII Encontro Regional de História. O historiador e seu tempo. ANPUH/SP - UNESP, 2014. Assis, SP. 2006. Cd-rom.

LORENZI, H.; MATOS, J. F. A. Plantas medicinais no Brasil: nativas e exóticas. $2^{\text {a }}$. ed. Nova Odessa: Instituto Plantarum. 2008.

MACIEL, M. A. M.; PINTO, A. C.; VEIGA JÚNIOR, V. F.; GRYNBERG, N. F.; ECHEVARRIA, A. Plantas medicinais: a necessidade de estudos multidisciplinares. Revista Química Nova, v. 23, n. 3, p. 429-438. 2002. Disponível em: http://www.scielo.br/pdf/\%0D/qn/v25n3/9337.pdf. Acesso em: 12 dez. 2017.

MACIEL, M. R. A.; GUARIM NETO, G. Um olhar sobre as benzedeiras de Juruena (Mato Grosso, Brasil) e as plantas usadas para benzer e curar. Boletim do Museu Paraense Emílio Goeldi. Ciências humanas, v. 1, n. 3, p. 61-77, 2006.

MARIANO, N. F. De todas as cruzes de Mogi - O Divino Espírito Santo também faz a festa em Biritiba Ussu. In: Anais do XIX Encontro Nacional de Geografia Agrária, 2009, São Paulo. SP. 2009. p. 8575-8588.

MARIN, R. C.; SCORSOLINI-COMIN, F. Desfazendo o Mau-olhado: Magia, Saúde e Desenvolvimento no Ofício das Benzedeiras. Psicologia Ciência e Profissão, v. 37, p. 446-460, 2017.

MATTOS, G.; SOUSA, C. A.; BERTARELlO ZENI, A. L.; CAMARGO, A. Plantas medicinais e fitoterápicos na Atenção Primária em Saúde: percepção dos profissionais. Ciência \& Saúde Coletiva, [periódico na internet], 2016. Disponível em: http://www.cienciaesaudecoletiva.com.br/artigos/ plantas-medicinais-e-fitoterapicos-na-atencao-primaria-em-saude-percepcao-dos-profissionais/15946?id=15946 Acesso em: 02 jan. 2018. 
MEDEIROS, P. M.; FERREIRA JÚNIOR, W. S.; RAMOS, M. A.; SILVA, T. C.; LADIO, A. H.; ALBUQUERQUE, U. P. Why do people use exotic plants in their local medical systems? A systematic review based on Brazilian local communities. PLoS One, v. 12, p. e0185358, 2017.

MING, L. C.; SIlVA, S. M. P.; SIlVA, M. A. S.; HIDAlGO, A. F.; MARCHESE, J. A.; CHAVES, F. C. M. Manejo e cultivo de plantas medicinais: algumas reflexões sobre as perspectivas e necessidades no Brasil. Embrapa. Disponível em: https://www.agencia.cnptia.embrapa.br/Repositorio/Cultivo manejo plantas medicinais 000fmkg4dhc02wyiv80kxlb36j5p9pi9.PDF. Acesso em: 12 dez. 2017.

MINKOWSKI, W. L. Women healers of the middle ages: selected aspects of their history. American Journal of Public Health, v. 82, n. 2, p. 288-295, 1992.

OLIVEIRA, F. C. S.; BARROS, R. F. M.; MOITA NETO, J. M. Plantas medicinais utilizadas em comunidades rurais de Oeiras, semiárido piauiense. Revista Brasileira de Plantas Medicinais, v. 12, n. 3, p. 282-301, 2010.

OLIVEIRA, E. P.; TAQUES, E. M.; MOREIRA, P. V. S.; SIEBEN, C. R.; LORENZETTI, E. R. Plantas medicinais empregadas em benzimentos na região de Palmas - PR. Cadernos de Agroecologia, v. 11, n. 2, 2016. Disponível em: <http://revistas.aba-agroecologia.org.br/index.php/cad/article/view/21169>. Acesso em: 03 jan. 2018.

PASA, M. C.; SOARES, J. J.; GUARIM NETO, G. Estudo etnobotânico na comunidade de Conceição-Açu (alto da bacia do rio Aricá-Açu, MT, Brasil). Acta Botanica Brasilica, v.19, n. 2, p. 195-207, 2005.

RODRIGUES, H. Entre o espetáculo e a devoção: A Festa do Divino Espírito Santo em Mogi das Cruzes (SP). Dissertação de Mestrado. Programa de Pós-Graduação em Antropologia Social. FFCLCH. Universidade de São Paulo. SP. 2006.

SANTOS, F. V. O ofício das rezadeiras como patrimônio cultural: religiosidade e saberes de cura em Cruzeta na região do Seridó Potiguar. Revista CPC (USP), v. 08, p. 06-35, 2009.

SILVA, C. G.; MARINHO, M. G. V.; LUCENA, M. F. A.; COSTA, J. G. M. Levantamento etnobotânico de plantas medicinais em área de Caatinga na comunidade do Sítio Nazaré, município de Milagres, Ceará, Brasil. Revista Brasileira de Plantas Medicinais, v. 17, n. 1, p. 133-142, 2015. Disponível em $<$ http://www.scielo.br/scielo.php?script=sci_arttext\&pid=S1516$-05722015000100133 \& \operatorname{lng}=\mathrm{pt} \& \mathrm{nrm}=\mathrm{iso}>$. Acesso em: $22 \mathrm{dez} .2017$.

SOUSA, R. F. B. Pra curar tem que ter fé: Curandeiros, Benzedeiras e Rezadores - memórias de indivíduos numa perspectiva Histórica. In: Anais do XIV Encontro Estadual de História do Ceará, A Historiografia contemporânea e seu caráter libertário - As contribuições de MARC BLOCH. Fortaleza, CE. 
2014. Disponível em: http://uece.br/eventos/eehce2014/anais/trabalhos_completos/103-9359-10082014-221519.pdf . Acesso em: 12 jul. 2017.

TONGCO, M. D. C. Purposive sampling as a tool for informant selection. Ethnobotany Research \& Applications v. 5, p. 147-158, 2007.

VARELA, D. S. S.; AZEVEDO, D. M. Saberes e práticas fitoterápicas de médicos na estratégia saúde da família. Trabalho, Educação e Saúde, v. 12, n. 2, p. 273-290, 2014.

VEIGA JÚNIOR, V. F. Estudo do consumo de plantas medicinais na Região Centro-Norte do Estado do Rio de Janeiro: aceitação pelos profissionais de saúde e modo de uso pela população. Revista Brasileira de Farmacognosia, v. 18, n. 2, p. 308-313, 2008. Disponível em https://www.researchgate. net/profile/Valdir Veiga/publication/262496470 Study of the medicinal plants_consumption_in_the_Middle-North_Region_of_the_Rio_de_Janeiro State Acceptance by health professionals way of use of the population/ links/54b29d490cf28ebe92e2cf04.pdf Acesso em: 02 jan. 2018.

VIERTLER, R. B. Métodos antropológicos como ferramenta para estudo em etnobiologia e etnoecologia. Pp. 12-29. In: M.C.M. Amorozo; L.C. Ming \& S.M.P. Silva (orgs.). Métodos de coleta e análise de dados em etnobiologia, etnoecologia e disciplinas correlatas. Rio Claro, UNESP/CNPq. 2002.

VILLAS, T. P. C. O atroz uso da tortura como instrumento para obtenção de informações. AEQUITAS Virtual, v. 9, n. 23, p. 1-21, 2015. Disponível em http://p3.usal.edu.ar/index.php/aequitasvirtual/article/view/3477/4309. Acesso em: 12 dez 2017. 